\title{
Dihydroorotate Dehydrogenase Inhibitor
}

National Cancer Institute

\section{Source}

National Cancer Institute. Dihydroorotate Dehydrogenase Inhibitor. NCI Thesaurus.

Code C2169.

Any substance that inhibits dihydroorotate reductase, an enzyme required for de novo biosynthesis of pyrimidine. Inhibition of dihydroorotate reductase interferes with DNA and RNA synthesis. 